\title{
A percepção de residentes multiprofissionais da área da saúde sobre o processo de morte
}

\section{Healthcare multiprofessional residents' perception towards the dying process}

\section{Percepción de residentes multiprofesionales de la área de salud acerca del proceso de muerte}

\author{
Juliana Oliveira Perez ${ }^{1}$ \\ Dayane Regina dos Santos ${ }^{2}$ \\ Maribel Pelaez Dóro ${ }^{3}$
}

\begin{abstract}
RESUMO: A morte e o processo de morrer estão constantemente na rotina dos profissionais de saúde, porém, estes nem sempre estão preparados para lidar com estas questões. O objetivo do estudo é verificar a percepção dos profissionais residentes da área da saúde sobre a morte. Trata-se de uma pesquisa descritiva exploratória de abordagem quantitativa, realizada com 129 residentes em um hospital terciário, e contemplou nove profissões, com predominância feminina e idade média de 25anos (desvio padrão de 2,1 anos). Foi aplicada a Escala de Avaliação do Perfil de Atitudes Acerca da Morte (EAPAM). A maioria dos participantes (63\%) apresentou aceitação neutra em relação à morte, seguido de aceitação religiosa (16\%). Em terceiro lugar está o medo da morte (11\%). Por último, o evitamento e a aceitação de escape tiveram resultado similar (5\% cada). $\mathrm{O}$ perfil de atitude do profissional em relação à morte pode contribuir com o desenvolvimento da Síndrome de Burnout, prejudicando sua saúde e qualidade do serviço prestado.
\end{abstract}

Palavra-chave: Morte, Educação em relação à morte, Profissionais da saúde, Regulação emocional.

\begin{abstract}
Death and the dying process are constantly in the health professionals' routine, though they are not always prepared to deal with those issues. The objective of this study is to check the healthcare resident professionals' perception of death. It is a descriptive exploratory research with quantitative approach made with 129 residents in a tertiary hospital, and it covered nine professions, with female predominance and average age of 25 (standard deviation of 2.1 years).

1 Terapeuta Ocupacional formada pela Faculdade de Medicina de Ribeirão Preto da Universidade de São Paulo (FMR P-USP). Especialização em Atenção Hospitalar na área de oncohematologia. Hospital de Clínicas da Universidade Federal do Paraná (HC-UFPR). Curitiba, Paraná, Brasil. E-mail: ju.perez8390@gmail.com

2 Terapeuta Ocupacional graduada pela UFPR e mestre pelo Programa de Pós Graduação em Enfermagem da UFPR. Participante do Programa de Residência Integrada Multiprofissional em Atenção Hospitalar como preceptora, tutora e coordenadora da área de Terapia Ocupacional. Complexo Hospital de Clínicas da Universidade Federal do Paraná (HC-UFPR) (Curitiba, Paraná, Brasil); Universidade Federal do Paraná (UFPR) (Curitiba, Paraná, Brasil). Paraná, Brasil. E-mail: dayterapeuta@gmail.com

3 Possui graduação em Psicologia pela Universidade Tuiuti do Paraná (1981), mestrado em Psicologia da Infância e da Adolescência pela Universidade Federal do Paraná (2001) e doutorado em Ciências da Saúde pela Pós Graduação em Medicina Interna da Universidade Federal do Paraná (2008). É colaboradora à distância do Evanston Northwestern Healthcare Research institute. Hospital de Clínicas da Universidade Federal do Paraná (HC-UFPR) (Curitiba, Paraná, Brasil). Paraná, Brasil. E-mail: maripdoro@hotmail.com
\end{abstract}

ISSN 1982-8829 Tempus, actas de saúde colet, Brasília, 11(3), 179-192, 2017 - Epub mar, 2018 
The Death Attitude Profile Revised (DAP-R) was the instrument used. Most participants (63\%) had neutral acceptance of death, followed by religious acceptance (16\%). In third place is the fear of death $(11 \%)$. At last, the avoiding of death and the escape acceptance had similar results (5\% each). The professional's attitude profile toward death can contribute to the development of the Burnout Syndrome, which is harmful for their health and for the quality of the service done.

Keyword: Death and Dying, Death education, Health professional, Emotional regulation.

RESUMEN: La muerte y proceso de morir están constantemente en la rutina de profesionales de salud, pero no siempre están listos para hacer frente a esas cuestiones. El objetivo del estudio es verificar la percepción de profesionales residentes del área de salud sobre la muerte. Se trata de una investigación descriptiva exploratoria con abordaje cuantitativa, efectuada con 129 residentes de hospital terciario, e incluyó nueve profesiones, con predominio del sexo femenino y edad media de 25 años (desviación estándar de 2,1 años). Se aplicó la Escala de Evaluación del Perfil de Actitudes sobre la Muerte. La mayoría de los participantes (63\%) tuvieron una aceptación neutra en relación a la muerte, seguido de aceptación religiosa (16\%). En tercer lugar encuentra-se el miedo (11\%). Por último, evitación y aceptación del escape obtuvieron resultado similar (5\% cada uno). El perfil de actitud del profesional en relación a la muerte puede contribuir al desarrollo del Síndrome de Burnout, perjudicando su salud y calidad del servicio prestado.

Palabras clave: Muerte, Educación com relación a la muerte, Profesionales de la salud, Regulación emocional.

\section{INTRODUÇÃO}

Desde os primórdios, a temática morte acompanha o homem ${ }^{1}$, porém, apesar de ser um fenômeno antigo da natureza, ainda hoje permanece sem uma definição padrão ouro ${ }^{2}$. A morte é tida como uma experiência universal, que deve ser considerada como parte da experiência humana, ainda que cada pessoa a enfrente sozinha e de forma particular ${ }^{3}$.

As diferentes culturas sempre buscaram respostas para o mistério da morte através dos mitos, da filosofia, da arte e da religião ${ }^{1,4,5}$. Desta forma, devido à grande variedade de culturas que existiram no mundo e da mudança de pensamento através dos séculos, são distintas as formas de encarar a morte e o morrer através dos vários períodos da história ${ }^{6}$.

Na Idade Média, a morte era um acontecimento que envolvia toda a comunidade. O próprio moribundo, ao tomar consciência de sua morte, recolhia-se junto dos familiares, amigos e vizinhos cumprindo o ritual de pedir perdão pelas suas culpas, legar seus bens e tomar todas as precauções necessárias para o devido sepultamento ${ }^{1,7,8}$.

A partir do século XI, o homem começou a procurar garantias para a vida após a morte, através de ritos de absolvição dos pecados, orações, esmolas, donativos e missas. Os séculos seguintes, na Europa, são marcados pelo período da Morte Negra, em que havia pestes e epidemias por todas as regiões. Nesta época, eram realizadas inumações fora dos muros da cidade, e sempre que possível, era feita a cremação. Entre os séculos XIV e XVIII, a morte era vista como ameaça a todos de igual forma, sendo o mais importante garantir a vida após a morte e a salvação da alma ${ }^{8}$. 
Neste momento, procurava-se progressivamente isolar, separar, excluir os mortos dos vivos ${ }^{9} \mathrm{Na}$ segunda metade do século XIX, a morte passou a ser vista como algo vergonhoso e se tornou algo velado ${ }^{1}$.

Com o desenvolvimento de práticas de saúde no século XX, os padrões do adoecer e do morrer sofreram alterações. Atualmente, a morte é institucionalizada e medicalizada, e aparelhos de alta tecnologia são utilizados com o intuito de manter o organismo do paciente em funcionamento. Por estarmos inseridos em uma cultura capitalista, o doente é marginalizado por ter perdido seu papel funcional. Desta forma, há a necessidade de esconder a morte e os mortos da sociedade, justificando-se o fato desta se dar no ambiente hospitalar nos dias atuais ${ }^{6,10}$.

Entretanto, um dos agravantes da nossa cultura é que os profissionais de saúde estão despreparados para lidar com questões relacionadas à morte e ao processo de morrer ${ }^{11}$. Segundo estudo de Silva Junior et al. ${ }^{6}$, os sentimentos comumente despertados nos profissionais de saúde frente à morte são frustração, tristeza e impotência, que surgem em consequência da própria formação direcionada, na maioria das vezes, a recuperar a vida. Para Campelos ${ }^{1}$, médicos e enfermeiros que estão comumente em contato com pacientes terminais mostram, com frequência, comportamentos de evasão e outras formas de autoproteção, tendendo a abandoná-los por não conseguirem suportar a situação ou por se sentirem impotentes.

Os riscos ocupacionais nas unidades hospitalares são decorrentes, de maneira especial, da assistência direta prestada pelos profissionais de saúde a pacientes em diversos níveis de gravidade, na tensão emocional advinda do convívio com a dor, o sofrimento e, muitas vezes, da perda da vida $^{12}$.

Sendo assim, a morte, o processo de morrer e o luto estão constantemente na rotina dos profissionais da saúde ${ }^{1}$, pois estes tem um maior contato com o paciente, acompanhando-o até sua morte e realizando cuidados com o corpo ${ }^{5}$. Estes profissionais, então, estão sujeitos a estressores crônicos e comprometimentos psíquicos, ocasionados pelo próprio cotidiano ocupacional, que resulta em vulnerabilidade a riscos, doenças e agravos físicos, estresse e sofrimento mental ${ }^{7,13}$.

Para que os cuidados de fim de vida aconteçam de uma forma mais digna, é necessário que os profissionais de saúde reflitam e se questionem sobre o rito de passagem da vida para a morte e reconheçam o que mais os perturba e desperta medos e sentimentos incômodos, impedindo que haja um comportamento de fuga e evitamento do doente em fim de vida ou que o próprio profissional adoeça $a^{5,14}$.

Visto isso, a relevância do presente estudo está na necessidade de se discutir a temática de morte e morrer. A Associação Americana de Terapia Ocupacional ${ }^{15}$ descreve o desempenho ocupacional como o ato de realizar e alcançar uma ação selecionada (habilidade de desempenho), 
uma atividade ou ocupação e os resultados da relação dinâmica transacional entre o cliente, o contexto e a atividade. Dentro das habilidades de desempenho há a capacidade de regulação emocional, que pode afetar a capacidade de um indivíduo em responder de forma eficaz às exigências da ocupação ${ }^{15}$. Ou seja, o desempenho ocupacional do profissional de saúde pode estar relacionado à sua capacidade de regulação emocional diante de situações de morte e morrer. Faz-se necessário, então, aumentar a reflexão sobre essa temática e discutir a necessidade de uma intervenção junto aos profissionais atuantes, de educação continuada ou no momento em que estes adentram no cenário hospitalar a fim de elaborar estratégias que auxiliem na capacidade de regulação emocional e, consequentemente, que melhore o seu desempenho ocupacional diante de uma situação de morte no ambiente de trabalho, reduzindo riscos ocupacionais.

\section{DESENVOLVIMENTO}

\subsection{Objetivo}

Este estudo tem como objetivo verificar a percepção que os profissionais residentes da área da saúde têm sobre a morte.

\subsection{Metodologia}

Esta é uma pesquisa descritiva exploratória de abordagem quantitativa, realizada com 129 residentes do Programa de Residência Multiprofissional em Atenção Hospitalar (PRIMAH) de um hospital terciário do sul do Brasil. Inicialmente, o questionário seria aplicado a todos os 137 residentes em atividade no momento do estudo, entretanto 8 optaram em não participar. Trata-se de uma pós-graduação em nível de especialização, com duração de dois anos. Atualmente, neste programa de residência estão disponíveis seis áreas: cardiovascular; urgência e emergência; saúde da mulher; saúde do adulto e do idoso; saúde da criança e adolescente; oncologia e hematologia. Há vagas para as seguintes profissões: enfermagem, farmácia clínica e farmácia bioquímica, fisioterapia, nutrição, odontologia, psicologia, serviço social e terapia ocupacional.

A coleta de dados foi realizada no período de fevereiro a abril de 2015, através de dois instrumentos autoaplicáveis: um questionário sociodemográfico e a Escala de Avaliação do Perfil de Atitudes Acerca da Morte (EAPAM). Após aprovação do Comitê de Ética em Pesquisa (nº 931.188 de 11/01/2015), os dados foram coletados durante as atividades acadêmicas dos residentes.

O Questionário Sociodemográfico, elaborado para o presente estudo, contém nove itens, relevantes para traçar o perfil dos participantes da pesquisa.

A Escala de Avaliação do Perfil de Atitudes Acerca da Morte (EAPAM) é a versão portuguesa traduzida e validada por Loureiro ${ }^{16}$ do Death Attitude Profile Revised ou Perfil de Atitudes Acerca da Morte - revisto (DAP-R), de Wong, Reker, e Gesser ${ }^{17}$, que por sua vez, é uma versão revista e 
alargada da versão anterior de 1987 dos mesmos autores ${ }^{5 .}$

As respostas da EAPAM abrangem cinco dimensões: a aceitação religiosa, a aceitação neutra, a aceitação de escape, o medo da morte e o evitamento da morte. Esta escala é constituída por 32 itens, com estrutura do tipo Likert, de 1 a 7 , em que $1=$ discordo completamente e $7=$ concordo completamente ${ }^{3}$. Para cada dimensão, também é possível uma pontuação média que pode ser calculada dividindo-se o escore total pelo número de itens que fazem parte de cada dimensão ${ }^{17}$.

Os dados dos questionários aplicados foram registrados em planilhas do Microsoft Excel 2010 e a análise foi realizada pelo método de estatística descritiva simples, com análise dos dados brutos, frequência, média, mediana e percentual.

\subsection{Resultados}

Tabela 1. Características Demográficas da população

\begin{tabular}{lcc}
\hline & \multicolumn{2}{c}{ Participantes (n=129) } \\
\cline { 2 - 3 } Variáveis & $\mathrm{N}$ & $\%$ \\
\hline Sexo & & \\
Feminino & 120 & 93,02 \\
$\quad$ Masculino & 9 & 6,97 \\
Estado Civil & & \\
$\quad$ Solteiro & 103 & 79,84 \\
Casado & 21 & 16,27 \\
Outros & 5 & 3,87 \\
Religião & & \\
Católico & 64 & 50,39 \\
Nenhuma & 28 & 22,04 \\
Evangélico & 13 & 10,23 \\
Espírita & 12 & 9,44 \\
Agnóstico & 6 & 4,72 \\
Outros & 6 & 4,72 \\
Procedência & & \\
Paraná & 97 & 75,19 \\
São Paulo & 7 & 5,42 \\
Santa Catarina & 6 & 4,65 \\
Outros & 19 & 14,72 \\
\hline
\end{tabular}

A amostra foi composta por 129 participantes, conforme apresentado na Tabela 1, sendo que oito residentes convidados não aceitaram participar. A média de idade foi de 25 anos, variando entre 22 e 35 anos, e 93\% dos participantes (n=120) são do sexo feminino. Em relação ao estado civil, há predominância de solteiros $(80 \% ; n=103)$. No que diz respeito à religião, $50,3 \%(n=64)$ são católicos. A maioria dos participantes $(75 \% ; n=97)$ é procedente do estado do Paraná. 
Tabela 2. Perfil Profissional

\begin{tabular}{lcc} 
& \multicolumn{2}{c}{ Participantes $(\mathrm{n}=129)$} \\
\cline { 2 - 3 } Variáveis & $\mathrm{N}$ & $\%$ \\
\hline Categoria Profissional & 17 & 13,17 \\
Enfermagem & 8 & 6,20 \\
Farmácia Bioquímica & 17 & 13,17 \\
Farmácia Clínica & 21 & 16,27 \\
Fisioterapia & 18 & 13,95 \\
Nutrição & 2 & 1,55 \\
Odontologia & 27 & 20,93 \\
Psicologia & 2 & 1,55 \\
Serviço Social & 17 & 13,17 \\
Terapia Ocupacional & & \\
Programa & 34 & 26,35 \\
Atenção ao Adulto e Idoso & 30 & 23,25 \\
Oncologia e Hematologia & 22 & 17,05 \\
Urgência e Emergência & 18 & 13,95 \\
Cardiologia & 14 & 10,85 \\
Atenção à Saúde da Mulher & 11 & 8,52 \\
Atenção à Saúde da Criança e Adolescente & &
\end{tabular}

Os números de profissionais de cada categoria e área estão apresentados na Tabela 2. A maioria se graduou no ano de 2012 e a média de experiência em contexto hospitalar era de cinco meses antes de adentrar a residência. São 38 (29,5\%) participantes que já completaram os dois anos de residência (R3), 40 (31,0\%) estão no início do segundo ano (R2) e 51 (39,5\%) acabaram de ingressar no curso (R1).

A maioria dos participantes $(n=82 ; 63 \%)$ apresentou aceitação neutra em relação à morte, seguida de aceitação religiosa $(n=21 ; 16 \%)$. Em terceiro lugar está o medo da morte, que representou $11 \%$ da amostra $(n=14)$. O evitamento e a aceitação de escape tiveram o mesmo resultado, apresentando $5 \%(n=6)$ da amostra cada. Esses dados estão expostos no Gráfico 1.

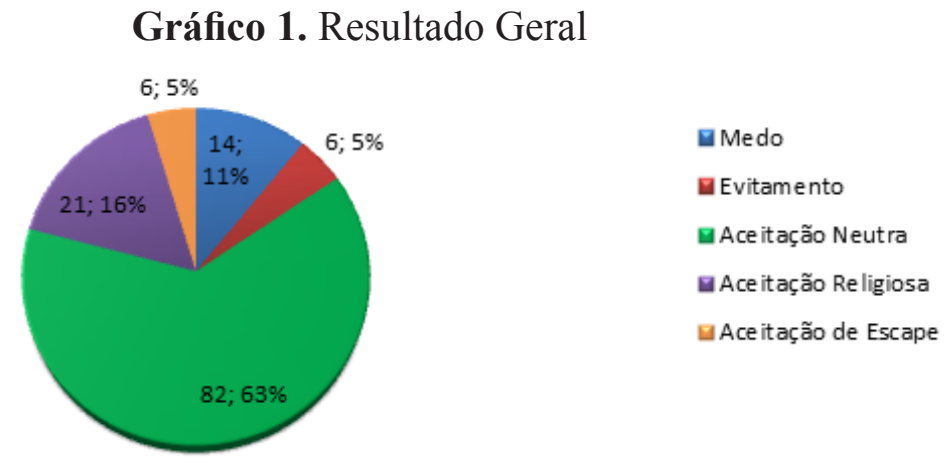

Segundo Wong et al. ${ }^{17}$ há dois tipos de atitude perante a morte: a aceitação ou temor, ou seja, o homem aceita ou teme a sua morte, levando em conta a forma como viveu e aceitou seu percurso ao longo da vida e dos significados que foi atribuindo 3 .

$\mathrm{Na}$ aceitação neutra, a morte é compreendida como uma parte integral da vida. Um ISSN 1982-8829 Tempus, actas de saúde colet, Brasília, 11(3), 179-192, 2017 - Epub mar, 2018 
indivíduo com este tipo de aceitação não teme a morte, mas também não a deseja ${ }^{16}$. A aceitação religiosa implica uma determinada crença religiosa e/ou espiritual, numa vida repleta de felicidade para além da morte, felicidade essa que será eterna ${ }^{17}$. Na aceitação de escape a morte surge como uma fuga do sofrimento, ou seja, é quando as condições de vida acarretam dor ou sofrimento aos mais diversos níveis e a morte pode significar alívio ou alternativa de escape para as dificuldades terrenas ${ }^{16}$.

O medo da morte emergiria da incapacidade do indivíduo em encontrar um significado pessoal e objetivo para sua vida e morte. O evitamento da morte é quando o indivíduo evita qualquer contato, pensamento ou atitude acerca da morte, a fim de reduzir a ansiedade perante a morte ${ }^{17}$.

Gráfico 2. Resultado por Ano de Experiência

\section{$\square$ Medo $\square$ Evitam ento $\square$ Aceitação Neutra $\square$ Aceitação Religiosa $\square$ Aceitação de Escape}
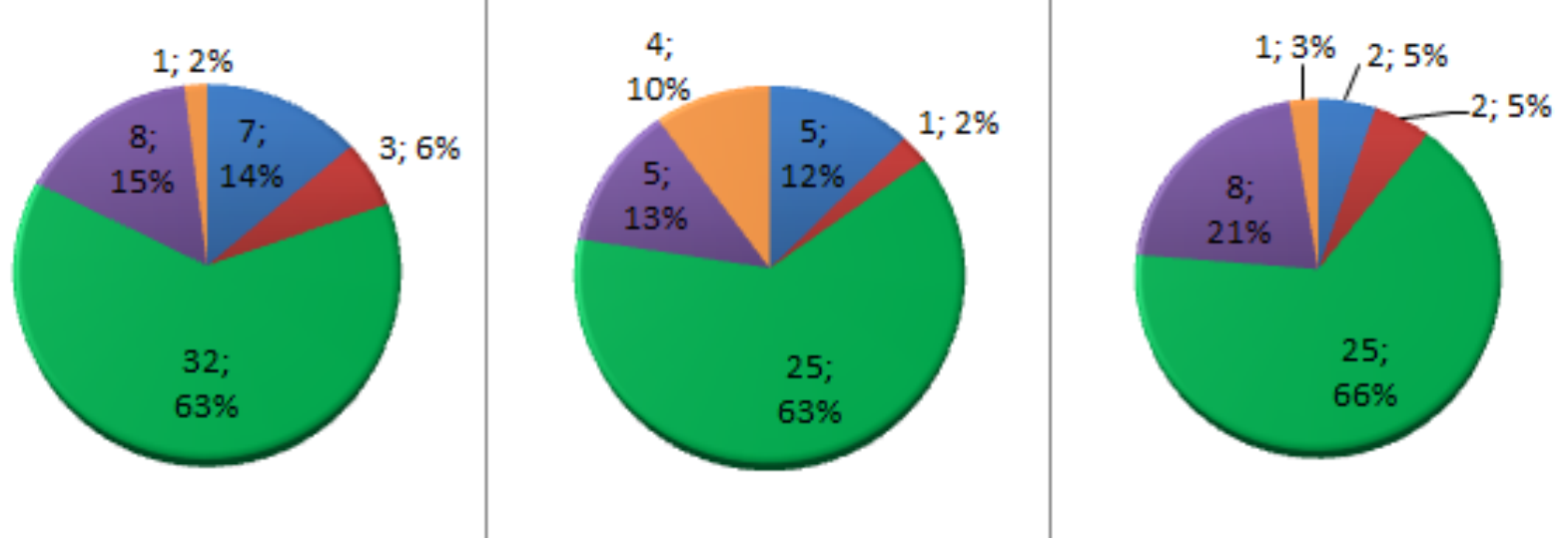

O gráfico da esquerda representa os R1 (residentes que acabaram de ingressar na residência), o gráfico do meio representa os R2 (residentes que estão iniciando o segundo ano); e o gráfico da direita representa os R3 (residentes que estão concluindo o segundo ano).

Nos resultados por ano de experiência na residência (Gráfico 2), manteve-se a predominância da aceitação neutra perante a morte, com maior porcentagem nos residentes que já completaram os dois anos de residência (R3), com 66\%. Tanto os residentes do segundo ano (R2), quanto os que acabaram de adentrar a residência $(\mathrm{R} 1), 63 \%$ mostraram aceitação neutra. Quanto à aceitação religiosa, apresentaram esse tipo de aceitação 15\% dos R1, 13\% dos R2 e 21\% dos R3. A aceitação de escape foi maior nos R2, correspondendo a 10\%, nos R3 são 3\% e nos R1 apenas 2\%. O medo da morte apareceu mais nos R1, correspondendo a 14\%, seguido de $12 \%$ de R2 e apenas 5\% de R3. O evitamento também se apresentou mais nos R1, sendo 6\%, seguido dos R3 com 5\% e R2 apenas $2 \%$. 
Gráfico 3. Resultados por profissão

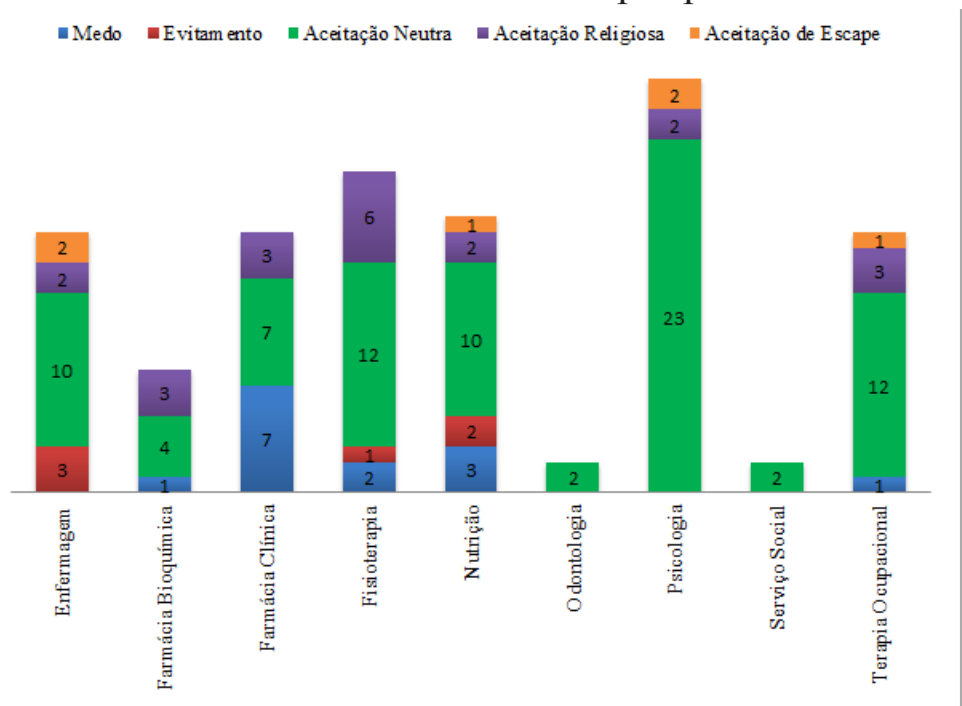

Também nos resultados por categoria profissional, a aceitação neutra apareceu predominantemente (Gráfico 3). Na enfermagem, 10 (58,9\%) apresentaram aceitação neutra, 2 $(11,7 \%)$ aceitação religiosa, $2(11,7 \%)$ aceitação de escape, 3 (17,6\%) apresentaram evitamento e não apareceu o medo. Na Farmácia Bioquímica, apenas 1 (12,5\%) demonstrou medo da morte, $3(37,5 \%)$ tiveram aceitação religiosa e $4(50,0 \%)$ aceitação neutra. A Farmácia Clínica foi a profissão com maior número de profissionais que apresentaram medo da morte, totalizando 7 $(41,2 \%)$, a mesma quantidade dos que apresentaram aceitação neutra $(7 ; 41,2 \%)$, e $3(17,6 \%)$ aceitação religiosa. Entre os fisioterapeutas, $12(57,1 \%)$ apresentaram aceitação neutra, $6(28,6 \%)$ aceitação religiosa, 2 (9,5\%) apresentaram medo e 1 (4,8\%) evitamento da morte. Os dois (100\%) odontologistas do grupo apresentaram aceitação neutra, assim como os dois (100\%) do serviço social. A psicologia demonstrou apenas formas de aceitação da morte, sendo que $23(85,2 \%)$ apresentaram aceitação neutra, 2 (7,4\%) aceitação religiosa e $2(7,4 \%)$ aceitação de escape. Entre os terapeutas ocupacionais, $12(70,6 \%)$ apresentaram aceitação neutra, $3(17,6 \%)$ aceitação religiosa, $1(5,9 \%)$ aceitação de escape e $1(5,9 \%)$ medo da morte.

Gráfico 4. Resultado por área

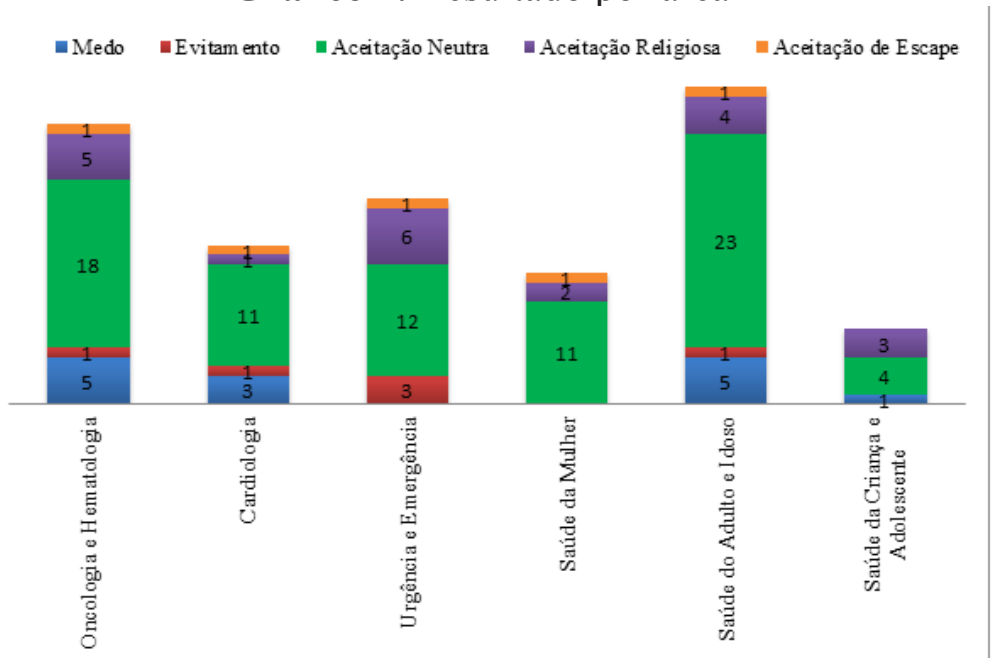

ISSN 1982-8829 Tempus, actas de saúde colet, Brasília, 11(3), 179-192, 2017 - Epub mar, 2018 
O Gráfico 4 mostra os resultados por área. Na Oncologia e Hematologia, foram 18 (60,0\%) participantes com aceitação neutra, seguido pelo medo da morte e aceitação religiosa, com 5 $(16,7 \%)$ profissionais em cada. Na cardiologia 11 (64,7\%) profissionais apresentaram aceitação neutra, seguido por 3 (17,6\%) com medo da morte. O Programa de Saúde do Adulto e Idoso também teve aceitação neutra seguida de medo da morte, com $23(67,6 \%)$ e $5(14,7 \%)$, respectivamente. A Urgência e Emergência teve 12 (54,5\%) profissionais com aceitação neutra, seguido de $6(27,3 \%)$ com aceitação religiosa, assim como na saúde da mulher, que teve $11(84,6 \%)$ e $2(15,4 \%)$, respectivamente. No programa da Saúde da Criança e Adolescente 4 (50,0\%) profissionais apresentam aceitação neutra, $3(37,5 \%)$ aceitação religiosa e apenas $1(12,5 \%)$ apresenta medo da morte.

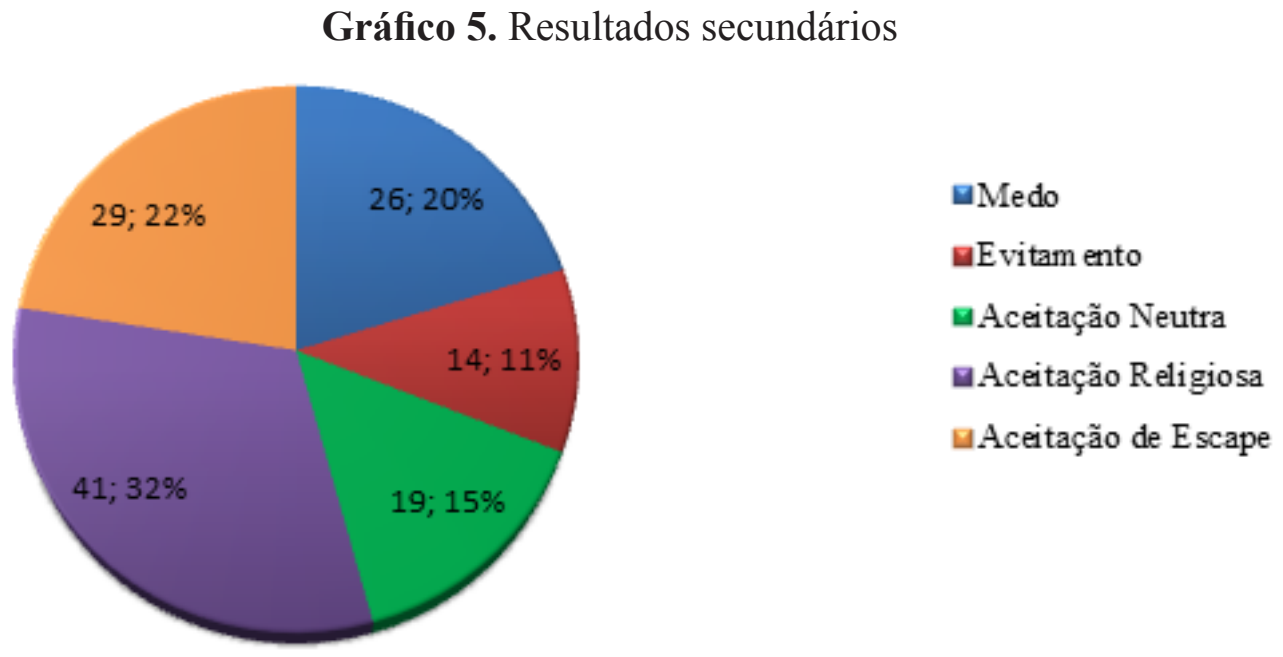

Os resultados foram analisados de forma mais aprofundada, considerando-se as dimensões que estariam como a segunda mais pontuada em cada profissional. $\mathrm{O}$ gráfico 5 mostra esses resultados de forma geral, sendo que $15 \%(n=19)$ dos participantes tiveram a aceitação neutra como a segunda mais pontuada, 32\% $(n=41)$ demonstraram aceitação religiosa, $22 \%(n=29)$ apresentaram aceitação de escape, $11 \%(n=14)$ têm como atitude o evitamento e $20 \%(n=26)$ apresentam medo da morte como segunda dimensão mais pontuada.

\subsection{Discussão}

Como visto nos resultados, a grande maioria dos residentes apresentou aceitação neutra perante a morte. Este tipo de aceitação da morte é caracterizado por ser uma abordagem mais naturalista ${ }^{18}$, e as pessoas que tem esta forma de aceitação tem a tendência para um funcionamento melhor adaptado, pois a morte é encarada como sendo algo inalterável e inevitável nas suas vidas, conseguindo assim, viver com qualidade e fazer um uso satisfatório dos seus dias ${ }^{17}$. Nessa pesquisa, a aceitação religiosa apareceu em segundo lugar, com 16\%, seguida do medo, com 11\%. Alguns autores afirmam que o medo da morte é menor em indivíduos com fortes convicções religiosas, independente de defenderem ou não a crença plena numa continuidade da vida após a morte ${ }^{8}$. A aceitação de escape e o evitamento ficaram empatados, sendo os que menos apareceram, com 5\% 
cada. Na aceitação de escape, a morte não é sentida necessariamente como boa, mas a vida é sentida como má e o evitamento é considerado um mecanismo de defesa psicológico para evitar que o tema chegue à consciência ${ }^{8}$. Podemos associar esse fato ao próprio contexto em que a pesquisa foi feita e onde os residentes desempenham seu trabalho, pois é muito difícil evitar a morte ou não entrar em contato com o sofrimento advindo do adoecimento estando em um hospital terciário.

O medo da morte foi mais evidente nos R1. Podemos inferir que os R1, por não terem ou terem tido pouquíssimo contato com o contexto hospitalar, não vivenciaram a morte na sua vida profissional, sendo este um assunto mistificado e pouco discutido, o que gera medo. Em contrapartida, os R3, ao passarem 2 anos neste contexto, e vivenciarem a morte em seu ambiente de trabalho, conseguiram desmistificar e melhorar a elaboração deste fenômeno. Um indício desta melhoria pode ser a porcentagem de aceitação neutra e religiosa ser maior nos R3 (66\% e 21\%).

O que chama atenção são os altos valores de aceitação de escape nos R2 (10\%) e evitamento nos R1 e R3 (6\% e 5\%). Esses valores podem estar associados ao mecanismo de defesa de dissociação do discurso, negação ou à racionalização. Desta forma, a atitude no âmbito emocional revela uma dificuldade de enfrentamento da situação de morte, diferentemente do que é visto no discurso ${ }^{19,20}$.

Quando analisamos os dados por profissão, percebemos que todas as categorias profissionais apresentaram a aceitação neutra como predominante. Porém, vale destacar alguns achados. A Psicologia foi a única profissão que apresentou apenas formas de aceitação da morte, seguida da Terapia Ocupacional, com apenas 1 profissional apresentando medo. Na Enfermagem, 3 residentes apresentam a atitude de evitamento da morte. Na farmácia clínica o número de profissionais que apresentaram medo é bastante alto, igualando-se aos que tem aceitação neutra, ou seja, 7 farmacêuticos. Esses dados mostram-se relevantes, pois os profissionais da saúde que apresentam níveis elevados de desgaste emocional mostram-se pouco satisfeitos com seu emprego e com sentimentos de autodesvalorização, além de apresentar maior consumo de álcool e drogas, mais distúrbios do sono, maiores dificuldades em se comunicar com os doentes e manifestam maior desejo de deixar de exercer sua profissão no futuro ${ }^{8}$.

Segundo Vachon*, em 1987, há uma forte motivação pessoal, ou propósito pessoal de vida, associado à escolha da área profissional com maior exposição à morte e que esta pode influenciar atitudes individuais perante a morte ${ }^{8}$. Nesse sentido, os profissionais residentes da saúde da mulher, programa em que há mais nascimentos do que óbitos, apresentaram apenas formas de aceitação da morte. No programa da Urgência e Emergência, em que há o maior número de óbitos, apesar de haver 3 profissionais que apresentaram evitamento, é significativo o número da aceitação religiosa apresentado por 6 profissionais. Mesmo com esta motivação ainda podemos perceber que, na Oncologia e Hematologia, existem 5 profissionais que tem medo da morte e 1 apresenta atitude de evitamento. Na cardiologia também são 3 profissionais que apresentam medo da morte e 5 no programa do adulto e idoso.

ISSN 1982-8829 Tempus, actas de saúde colet, Brasília, 11(3), 179-192, 2017 - Epub mar, 2018 
Porém, quando analisamos de maneira mais aprofundada os questionários, é possível perceber uma mudança significativa. Essa análise é importante por permitir uma avaliação para além do superficial, ou seja, para o conteúdo que está velado pelo discurso do sujeito. Os tipos de aceitação ainda são predominantes, porém, o evitamento e medo passam a ser relevantes, sendo de $11 \%$ e $20 \%$ respectivamente. A aceitação religiosa dobra seu valor, passando de $16 \%$ para $32 \%$, a aceitação de escape que era apenas $5 \%$ passa a corresponder a $22 \%$, e a aceitação neutra que correspondia a $63 \%$, diminui para 15\%. Isto nos leva a acreditar que a aceitação é parte apenas do discurso, pois esta não é coerente com o evitamento e medo apresentados quando os resultados são olhados de forma mais profunda. No discurso está presente a racionalização ou intelectualização, um mecanismo de defesa que responde através dos recursos do intelecto, sendo que a emoção fica represada e não é elaborada, gerando, a longo prazo, tensão, angústia, estresse e sofrimento psíquico $^{19,20}$.

Os profissionais das diversas áreas ficam, assim, expostos a um tipo de desgaste intenso e constante, apresentando dificuldades especiais ao enfrentarem a imprevisibilidade da vida, a fragilidade humana e a terminalidade do doente. A negação mantém-se presente nos profissionais de saúde que evitam os doentes em estado terminal e a falar sobre as mortes dos pacientes ou sentimentos despertados neles próprios quando estas ocorreram ${ }^{21}$. Kubler-Ross ${ }^{22}$ questiona como seria possível um profissional da saúde ajudar um paciente terminal se ele próprio não encara a morte com serenidade. Como apresentado no estudo de Steinhauser, Clipp, McNeily, Cristakis, Mcintyre, \& Tulsky*, em 2000, há um sentimento de tristeza e culpabilidade por parte dos profissionais da equipe face a pacientes que morreram em sofrimento ${ }^{8}$.

Sendo assim, dependendo do perfil de atitude que o profissional tem diante da morte, ele pode manifestar fatores considerados de risco para o desenvolvimento da Síndrome de Burnout, como o esgotamento emocional, despersonalização e sentimento de realização diminuído, estresse, insatisfação e não elaboração das perdas, o que gera angústia e tensão, culpabilidade e tristeza.

Quando isso acontece, há um esfriamento afetivo que interfere no seu relacionamento interpessoal e reduz sua produtividade. A presença de Burnout nos profissionais de saúde prejudica a qualidade do serviço prestado e traz consequências para a vida do trabalhador, tais como depressão, absenteísmo, presenteísmo, e dificuldades nas relações familiares e sociais. O indivíduo torna-se, então, incapaz de se envolver emocionalmente em seu ambiente de trabalho ${ }^{23}$.

\section{CONCLUSÃO}

Este estudo permitiu verificar a percepção que os profissionais residentes da área da saúde têm sobre a morte. Pudemos comparar as diferenças entre as categorias profissionais, assim como semelhanças sobre o assunto que variam de acordo com a área de atuação e a população que atende 
na área hospitalar.

Além disso, foi possível perceber que há um discurso aparente de atitude de aceitação neutra diante da morte, ou seja, que esta é compreendida como uma parte integral da vida, sendo algo inalterável. Porém, ao se analisar o questionário de maneira mais aprofundada percebeu-se algo velado, pois há porcentagens significativas de aceitação religiosa, aceitação de escape e medo da morte. Como visto, este quadro pode levar ao desenvolvimento da Síndrome de Burnout, a redução da qualidade do trabalho e assistência prestada, dificuldade de relacionamentos, evitamento, distanciamento dos pacientes, absenteísmo e presenteísmo. Assim, destaca-se a necessidade de um olhar cuidadoso para os residentes, com a promoção de grupos de discussão, espaços de reflexão e compartilhamento, acolhimentos, atividades educativas, orientação sobre estresse e estratégias de enfrentamento e prevenção do Burnout. Como limitação, destaca-se que o questionário não foi reaplicado no mesmo participante nos diferentes momentos durante a sua residência, o que nos possibilitaria verificar se há uma mudança na atitude perante a morte de um mesmo residente durante esse processo.

\section{REFERÊNCIAS}

1. Campelos ICSF. A ansiedade e o medo da morte nos profissionais de saúde [Monografia] [Internet]. Porto: Universidade Fernando Pessoa; 2006. [acesso em 2017 jan 15]. Disponível em:

http://bdigital.ufp.pt/bitstream/10284/1012/2/Monografia.pdf

2. Santos FS. Conceituando Morte. In: Santos FS. Cuidados paliativos - Discutindo a vida, a morte e o morrer. São Paulo: Atheneu; 2009. p. 301-318.

3. Pinto SFS. A influência das atitudes e da ansiedade face à morte na imortalidade simbólica em estudantes. [Dissertação de Mestrado] [Internet]. Lisboa: Universidade Lusófona de Humanidades e Tecnologias; 2011. [acesso em 2017 jan 15]. Disponível em:

http://recil.grupolusofona.pt/bitstream/handle/10437/1692/Tese\%20Final.pdf?sequence=1

4. Caputo RF. O homem e suas representações sobre a morte e o morrer: um percurso histórico. Rev. Multidisciplinar da Uniesp. [Internet]. 2008 [acesso em 2017 jan 15]; Dez (6): 73-80. Disponível em: http://www.uniesp.provisorio. ws/revista/revista6/pdf/8.pdf

5. Serra SSS. Morrer na presença de quem cuida: Atitudes do enfermeiro de cuidados diferenciados face à morte e aos cuidados ao doente em fim de vida [Tese de Mestrado] [Internet]. Porto: Faculdade de Medicina da Universidade do Porto; 2012. [acesso em 2017 jan 15]. Disponível em:

https://repositorio-aberto.up.pt/bitstream/10216/72951/2/80751.pdf

6. Silva Junior FJG, Santos LCS, Moura PVS, Melo BMS, Monteiro CFS. Processo de morte e morrer: evidências da literatura científica de enfermagem. Rev. Bras. Enferm. [Internet]. 2011 [acesso em 2017 jan 15]; 64(6): 1122-6. Disponível em: http://dx.doi.org/10.1590/S0034-71672011000600020

7. Aquino TAA, Serafim TDB, da Silva HDM, Barbosa, EL, Cirne, AA, Ferreira, FR, Dantas, PRS. Visões de morte, ansiedade e sentido de vida: um estudo correlacional. Psicologia Argumento [Internet]. 2010. [acesso em 2017 jan 15]; 28(63): 289-302. Disponível em www2.pucpr.br/reol/index.php/PA?dd1=3919\&dd99=pdf.

8. Andrade TAM. Atitudes perante a morte e sentido da vida em profissionais de saúde [Tese de Doutorado] [Internet]. Lisboa: Universidade de Lisboa; 2007. [acesso em 2017 jan 15]. Disponível em:

ISSN 1982-8829 Tempus, actas de saúde colet, Brasília, 11(3), 179-192, 2017 - Epub mar, 2018 
http://repositorio.ul.pt/bitstream/10451/975/1/16424_Tese_Teresa_Andrade_versfinal.pdf

9. Combinato DS, Queiroz MS. Morte: uma visão psicossocial. Estudos de Psicologia [Internet]. 2006 [acesso em 2017 jan 15]; 11(2): 209-216. Disponível em: http://dx.doi.org/10.1590/S1413-294X2006000200010

10. Medeiros LA, Lustosa MA. A difícil tarefa de falar sobre morte no hospital. Rev. SBPH [Internet]. 2011 [acesso em 2017 nov 15]; 14(2): 203-227. Disponível em: http://pepsic.bvsalud.org/scielo.php?pid=S1516$\underline{08582011000200013 \& \text { script }=\text { sci arttext }}$

11. Gutierrez BAO, Ciampone MHT. O processo de morrer e a morte no enfoque dos profissionais de enfermagem de UTIs. Revista Escola Enfermagem USP [Internet]. 2007 [acesso em 2017 jan 15]; 41(4): 660-667. Disponível em: http://dx.doi.org/10.1590/S0080-62342007000400017.

12. Bulhões I. Riscos do trabalho de enfermagem. $2^{\mathrm{a}}$ ed. Rio de Janeiro, Rio de Janeiro: Ed. Folha Carioca; 1994.

13. Santos MA, Aoki FCOS, Oliveira-Cardoso, EA. Significado da morte para médicos frente à situação de terminalidade de pacientes submetidos ao Transplante de Medula Óssea. Ciência \& Saúde Coletiva [Internet]. 2013. [acesso em 2017 jan 15]; 18 (9): 2625-2634. Disponível em:

http://dx.doi.org/10.1590/S1413-81232013000900017

14. Alencar SCS, Lacerda MR, Centa ML. Finitude humana e enfermagem: reflexões sobre o (des)cuidado integral e humanizado ao paciente e seus familiares durante o processo de morrer. Fam. Saúde Desenv. [Internet]. 2005 [acesso em 2017 jan 15]; 7(2):171-180. Disponível em:

http://ojs.c3sl.ufpr.br/ojs2/index.php/refased/article/viewFile/8045/5668

15. American Occupational Therapy Association (AOTA). Occupational therapy practice framework: Domain and process. American Journal of Occupational Therapy [Internet]. 2014 [acesso em 2017 jan 15]; 68 (Suppl.1): S1S48. Disponível em: http://www.terapia-ocupacional.org.ar/wp-content/uploads/2014/05/3\%C2\%AA-EdicionMarco-de-Trabajo-2013.pdf

16. Loureiro LMJ. Tradução e adaptação da versão revista da Escala de Avaliação do Perfil de Atitudes Acerca da Morte (EAPAM) [Artigo de Investigação]. Revista de Enfermagem Referência [Internet]. 2010 [acesso em 2017 jan 15]; 3(1): 101-108. Disponível em: http://dx.doi.org/10.12707/RII1012

17. Wong P, Reker G, Gesser G. Death attitude profile revised: a multidimensional measure of attitude toward death. In: Neimeyer R. Death anxiety handbook: research, instrumentation, and application. Washington: Taylor \& Francis ed. lit; 1994. p. 121-148.

18. Lopes TPAV. Atitudes perante a morte e ansiedade e depressão em cuidadores profissionais de Cuidados Paliativos [Tese de Mestrado] [Internet]. Lisboa: Universidade de Lisboa; 2010. [acesso em 2017 jan 15]. Disponível em: http://repositorio.ul.pt/bitstream/10451/2638/1/ulfp037455_tm.pdf

19. American Psychiatric Association (APA). DSM-V: manual diagnóstico e estatístico de transtornos mentais. [Nascimento MIC et al, Trad.]. Porto Alegre: Artmed; 2014.

20. Borges MS, Mendes N. Representações de profissionais de saúde sobre a morte e o processo de morrer. Revista Brasileira de Enfermagem [Internet]. 2012 [acesso em 2017 jan 15]; 65(2): 324-331. Disponível em: http://dx.doi. org/10.1590/S0034-71672012000200019.

21. Oliveira ECN. O psicólogo na UTI: Reflexões sobre a saúde, vida e morte nossa de cada dia. Psicologia: Ciência e Profissão [Internet]. 2002 [acesso em 2017 jan 15]; 22(2): 30-41. Disponível em: http://dx.doi.org/10.1590/ $\underline{\text { s1414-98932002000200005 }}$

22. Kübler-Ross E. Sobre a morte e o morrer: o que o doente têm a ensinar a médicos, enfermeiras, religiosos e a seus próprios parentes [Menezes P, Trad]. $7^{\mathrm{a}}$ ed. São Paulo, Brasil: Martins Fontes; 1996.

23. Guido LA, Silva RM, Goulart CT, Bolzan MEO, Lopes LFD. Síndrome de Burnout em residentes multiprofissionais de uma universidade pública. Rev Esc Enferm USP [Internet]. 2012 [acesso em 2017 jan 15]; 46(6): 1477-83.

ISSN 1982-8829 Tempus, actas de saúde colet, Brasília, 11(3), 179-192, 2017 - Epub mar, 2018 
Disponível em: http://dx.doi.org/10.1590/S0080-62342012000600027

Artigo apresentado em 27/01/2017

Artigo aprovado em 26/02/2018

Artigo publicado no sistema em 16/04/2018

ISSN 1982-8829 Tempus, actas de saúde colet, Brasília, 11(3), 179-192, 2017 - Epub mar, 2018 